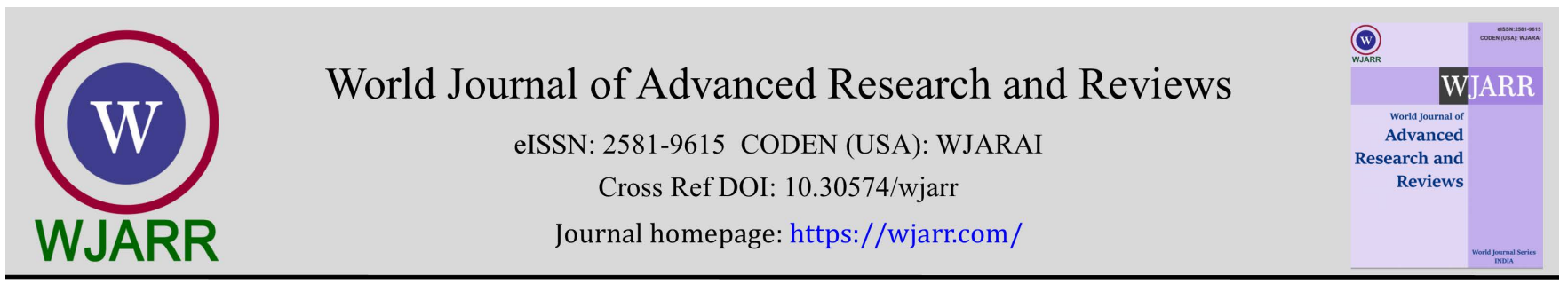

(RESEARCh ARTICLE)

Check for updates

\title{
Short - versus - long course antibiotics in catheterized patients undergoing transurethral resection of prostate
}

Orgeness Jasper Mbwambo 1, 3, *, James Samwel Ngocho 2, Emmanuel Mtui 2, Philemon Rune 2,3, Frank Bright 1,3 and Alfred Kien Mteta 1,3

${ }^{1}$ Department of Urology, Kilimanjaro Christian Medical University College, Moshi, Tanzania.

2 Department of Epidemiology and Biostatistics, Institute of Public Health, Kilimanjaro Christian Medical University College, Moshi, Tanzania.

${ }^{3}$ Kilimanjaro Christian Medical Centre, P.O. Box 3010, Moshi, Tanzania.

World Journal of Advanced Research and Reviews, 2021, 10(03), 173-179

Publication history: Received on 30 April 2021; revised on 06 June 2021; accepted on 09 June 2021

Article DOI: https://doi.org/10.30574/wjarr.2021.10.3.0260

\begin{abstract}
Introduction: The duration of peri-operative antibiotic treatment for patients undergoing Trans Urethral Resection of the Urostate (TURP) and who have been catheterized pre-operatively, remains undecided. The efficacy of a short-versus a traditional long-course antibiotic regime was investigated in preventing post-operative bacteriuria for catheterized patients undergoing TURP at a single centre.
\end{abstract}

Methodology: A randomized single blind, single centre clinical trial was conducted between September 2017 and May 2018. Patients were randomized into two groups (1:1). The control group received peri-operative antibiotics for 8 days and the intervention group for 3 days. Urinalysis and urine culture were performed pre-operatively, and postoperatively on day 2 and days 9 to 11, following TURP. All patients were followed up for 30 days after surgery for signs and symptoms of infectious complications.

Results: A total of 83 patients were enrolled in the study. 78 patients were evaluable until day 2 and 66 until days 9 to 11. The incidence of bacteriuria at days 9 to 11 following TURP were $40 \%$ and $38.7 \%$ in the intervention (short-course) and control (long-course) groups respectively (RR 1.03, 95\% CI 0.097 to 2.573). The incidence of Symptomatic Urinary Tract Infections (UTI) at the same time was $11.4 \%$ and $9.7 \%$ in intervention and control groups respectively (RR 1.27 , 95\% CI 0.10 to 2.57). None of the patients enrolled in the study developed clinical sepsis nor required re-admission during the follow up period.

Conclusion: A short- course antibiotic is as effective as a long course in preventing infectious complications in catheterized patients undergoing TURP.

Keywords: Antibiotic; Catheterized; Prostate surgery; Antimicrobial stewardship

\section{Introduction}

Benign prostatic hyperplasia (BPH) is one of the commonest medical conditions affecting elderly men. It occurs in $8 \%$ of men at the age of 40 years rising to $50 \%$ and $90 \%$ by the age of 60 and 80 years respectively [1].Transurethral resection of the prostate (TURP) remains the gold standard surgical procedure for the management of BPH. Worldwide, TURP is one of the most commonly performed Urological procedures (150,000 per year in US) [2]. It is the commonest urological operation at our institution with over 300 procedures each year.

\footnotetext{
${ }^{*}$ Corresponding author: Orgeness Jasper Mbwambo

Department of Urology, Kilimanjaro Christian Medical University college, Moshi,Tanzania.

Copyright $(2021$ Author(s) retain the copyright of this article. This article is published under the terms of the Creative Commons Attribution Liscense 4.0.
} 
Infectious complications are common following TURP and include asymptomatic bacteriuria (ABU), symptomatic urinary tract infections (UTI) and clinical sepsis. The incidence of asymptomatic bacteriuria ranges from 6 -64 \%, symptomatic UTI from $1.7 \%$ to $21.6 \%$, and sepsis from 1-4\% [3-5].Data from other colleagues in sub-Saharan Africa shows an incidence of $15 \%$ for symptomatic UTI [6].

A short course and even single dose antimicrobial prophylaxis has been shown to be effective in reducing post-operative infections in low risk patients undergoing TURP [7,8]. However, most randomized clinical trials (RCT) which studied short course antimicrobial prophylaxis excluded patients with bacteriuria and indwelling catheter[3- 10]. Therefore, the exact duration of antibiotic prophylaxis for men with a pre-operative urinary catheter, who are at higher risk of sepsis complications, is still debated. Moreover, the world-wide misuse of antibiotics is associated with an increase in drug resistance, secondary morbidity and increase in health care costs [9-11].This demands a rational use of antibiotics and antimicrobial stewardship programs.

The current practice in our institution has been to give a long peri-operative course of antibiotic coverage to patients undergoing TURP and considered at higher risk of septic complications. This include pre-operatively catheterized men who are in majority (60\% from Kilimanjaro Christian Medical Centre theatre registry). We therefore wanted to study whether a short-course antibiotic given peri-operatively was as effective in preventing post-operative septic complications in this patient group.

\section{Methodology}

\subsection{Study design and settings}

This study was designed as a randomized, single blind clinical trial, conducted between September 2017 and May 2018 at the Kilimanjaro Christian Medical Centre (KCMC), Moshi, Tanzania.

All men with Bladder Outlet Obstruction (BOO) and treated with indwelling catheter and admitted for TURP during the study period, were included. Exclusion criteria were patients with renal failure, uncontrolled diabetes mellitus, known HIV positivity and patients who had received antibiotics in the seven days prior to surgery. In addition, patients with bacteria resistant to gentamicin and/or ciprofloxacin identified in urine culture were excluded. Written informed consent was obtained prior to randomization. Patients were randomized into routine long (control) and short (intervention) course peri-operative antibiotic course. Computer generated randomization used blocks of 4 and allocation ratio 1:1 and was delivered to the clinical research team using a sealed envelope technique. Other doctors, nurses and laboratory technician were blinded to treatment allocation.

\subsection{Antibiotic regimen}

The control (long-course) group received intravenous gentamicin $160 \mathrm{mg}$ thirty minutes before surgery and 2 further doses on postoperative day 1 and 2 followed by oral ciprofloxacin tablet $500 \mathrm{mg}$ twice a day for five days. The intervention (short-course) only received intravenous gentamicin $160 \mathrm{mg}$ thirty minutes before surgery and 2 further doses on post-operative day 1 and 2. Catheter removal took place 48 hours following TURP in both control and intervention groups. Patients were discharged on day 2 post-operatively unless the patient experienced fever or other complications which required further hospital investigation and care. Compliance with antibiotic treatment in the control group, after discharge, was determined by telephone follow-up. All other treatments were similar between control and intervention groups.

\subsection{Study outcome}

The primary outcome was the incidence of post-operative bacteriuria. Secondary outcomes were incidence of symptomatic UTI, fever and clinical sepsis.

\subsection{Investigations}

Routine pre-operative blood tests included full blood count, creatinine, blood glucose, and prostate specific antigen. In addition an abdominal pelvic ultrasound, and urine culture and sensitivity were performed pre-operatively. Urine culture and sensitivity is a routine investigation for catheterized patients prior to surgery. Post-operatively physiological clinical signs (temperature, pulse rate, blood pressure, and respiratory rate) were recorded twice a day. Urinalysis, culture and sensitivity were performed on day 2 (following catheter removal) and between day 9 and 11 post-operative. After discharge, patients were followed up by telephone for 30 days, for symptoms and signs of sepsis. 
Blood film for malaria parasites and blood cultures were performed if patients develop a pyrexia greater than $38.5^{\circ} \mathrm{C}$ for more than 24 . Bacteriuria was defined as urine culture growth of $\geq 10^{5}$ colony forming units $/ \mathrm{ml}$. Symptomatic UTI was defined as symptoms related to UTI and significant urine bacterial growth. Sepsis was defined as suspected urinary infection and the presence of the systemic inflammatory response syndrome, SIRS [5]

\subsection{Sample size calculation}

The lack of similar studies in countries with limited resources in general and Sub-Saharan Africa in particular made it difficult to identify practical statistical figures to base the sample size calculations on. We therefore opted to use observations from earlier studies [13]. Considering the observed difference in postoperative bacteriuria in preoperatively catheterized/bacteriuric patients at 25\% (35\% in short-course versus $10 \%$ in long-course regimens) and using the formula for non-inferiority in randomized clinical trials [14]. The sample size at a confidence level of $95 \%$ was determined at $80.10 \%$ were added to compensate for loss of follow-up.

\subsection{Statistical calculations}

Continuous variables were analyzed during student's t test for parametric and Man Whitney U test for non-parametric data. Categorical variables were analyzed using chi square test and fisher's exact test. A p value of $<0.05$ was considered statistically significant. All analyses were performed using SPSS version 20.

\section{Results}

Peri-operative clinical characteristics of patients recruited to short- and long- courses were equivalent and are summarized in Table 1.

Table 1: Perioperative clinical characteristics

\begin{tabular}{|c|c|c|c|}
\hline Parameters & $\begin{array}{l}\text { Short Course antibiotics } \\
\mathrm{n}=41(51 \%)\end{array}$ & $\begin{array}{l}\text { Long course antibiotics } \\
n=39(49 \%)\end{array}$ & $\begin{array}{l}P \\
\text { value }\end{array}$ \\
\hline Age, yrs, mean (SD) & $71.71(10.7)$ & $74.21(7.7)$ & 0.2 \\
\hline Creatinine $\mu \mathrm{mol} / \mathrm{L}$ mean (SD) & $79.54(15.7)$ & $82.28(17.3)$ & 0.46 \\
\hline Haemoglobin g.dl mean (SD) & $13.33(1.4)$ & $13.26(1.4)$ & 0.83 \\
\hline $\begin{array}{l}\text { Preoperative duration of } \\
\text { catheterization,days,median (range)* }\end{array}$ & $35.50(174.0)$ & $61.00(331.0)$ & 0.13 \\
\hline $\begin{array}{l}\text { Pre-operative urine culture }{ }^{* * *} \\
\text { Positive bacteriuria } \mathrm{n}(\%)\end{array}$ & $24.00(58.5)$ & $27.00(69.2)$ & 0.32 \\
\hline $\begin{array}{l}\text { Weight of resected tissue, } g \text { median } \\
\text { (range) }{ }^{*}=68\end{array}$ & $23.00(75.0)$ & $22.50(81.0)$ & 0.65 \\
\hline
\end{tabular}

During the study period, a total of 83 patients met the inclusion criteria and were enrolled in the study (see Figure 1). After enrollment three patients were withdrawn from the study since surgery was cancelled because of high blood pressure $(n=2)$ and surgery no longer required $(n=1)$, because of a revised diagnosis of neurogenic bladder following diagnostic endoscopy. Six (7.5\%) patients went into urine retention following catheter removal. 9 patients were lost to follow up (11.3\%). Data was available post-operatively for 78 (97.5\%) patients until day 2 (39 intervention and 39 control), and $66(82.5 \%)$ patients until days 9 to 11 (35 intervention and 31 control group).

Pre-operative asymptomatic bacteriuria was present in 58\% (24/41) and 69\% (27/39) of the short- and long-course groups, respectively $(\mathrm{p}=0.32)$. 


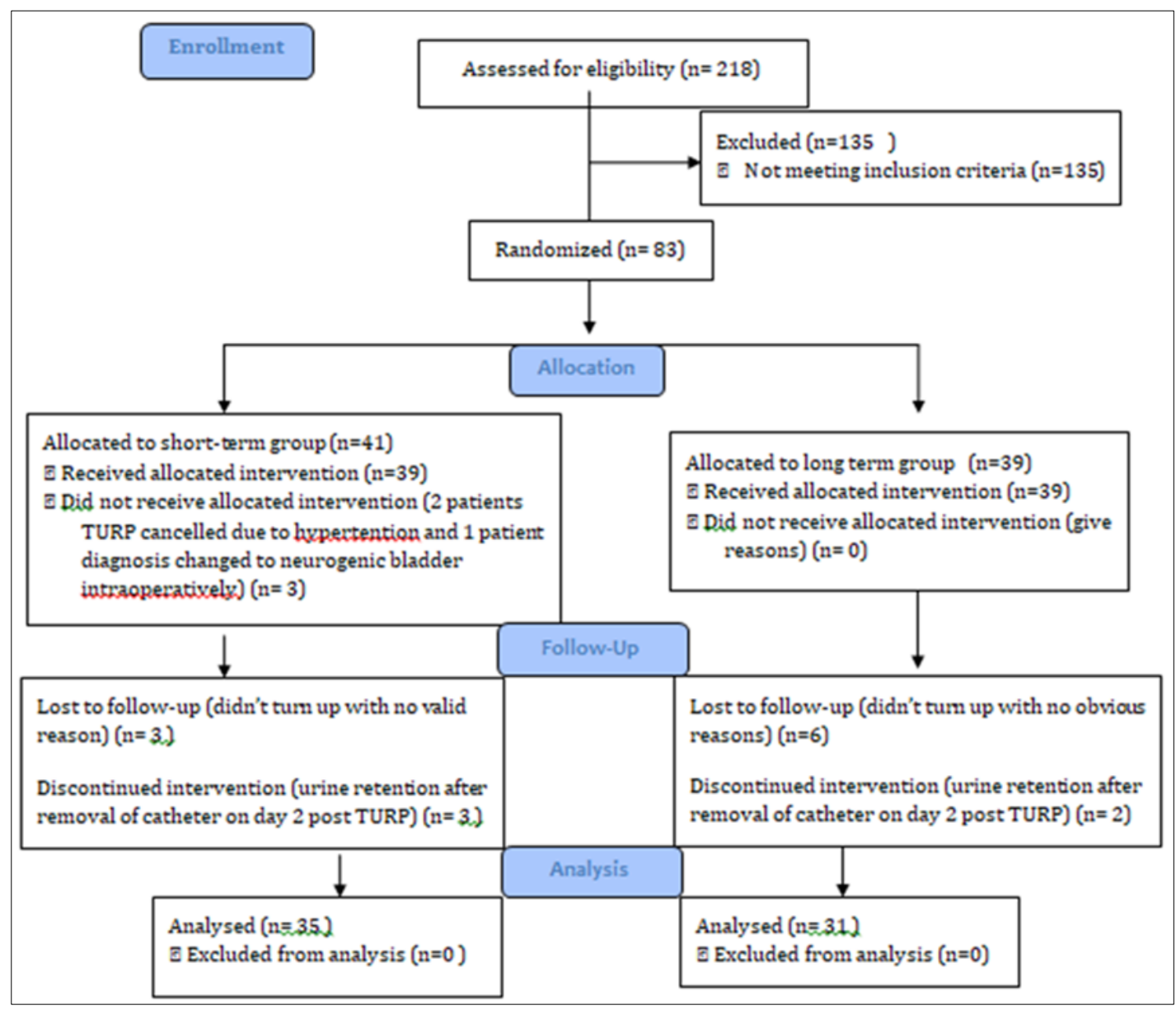

Figure 1 Flow chart with total number of enrolled patients and the number of patients who were evaluable up to end of study

Table 2 Incidence of bacteriuria day 2 post TURP

\begin{tabular}{|c|c|c|c|c|c|}
\hline $\begin{array}{l}\text { Antibiotic prophylaxis } \\
\text { group }\end{array}$ & $n=78$ & $\begin{array}{c}\text { Bacteriuria Incidence } \\
\text { n (\%) }\end{array}$ & $\begin{array}{l}\text { Relative Risk } \\
\text { (RR) }\end{array}$ & $95 \% \mathrm{CI}$ & $P$ value \\
\hline Short course & 39 & $2(5.10)$ & \multirow[t]{2}{*}{0.5} & \multirow[t]{2}{*}{$0.10-2.57$} & \multirow[t]{2}{*}{$0.68^{* * *}$} \\
\hline Long course & 39 & $4(10.30)$ & & & \\
\hline
\end{tabular}

Table 3 Incidence of Bacteriuria day's 9-11 post TURP

\begin{tabular}{|l|c|c|c|c|c|}
\hline $\begin{array}{l}\text { Antibiotic } \\
\text { prophylaxis } \\
\text { group }\end{array}$ & $\mathbf{n = 6 6}$ & $\begin{array}{l}\text { Bacteriuria Incidence n } \\
\text { (\%) }\end{array}$ & $\begin{array}{l}\text { Relative Risk } \\
\text { (RR) }\end{array}$ & $\mathbf{9 5 \%}$ CI & P value \\
\cline { 1 - 4 } Short course & 35 & $14(40.0)$ & 1.03 & $0.10-2.57$ & 0.92 \\
\cline { 1 - 3 } Long course & 31 & $12(38.7)$ & & \\
\hline \multicolumn{4}{|c|}{ CI, confidence interval; $(\%)$, proportion of patients with bacteriuria } \\
\hline
\end{tabular}

Data for post-operative bacteriuria and symptomatic UTI are shown in tables 2, 3 and 4. One patient in each of the shortand long- course antibiotic groups experienced fever days 9-11 following TURP $(\mathrm{p}=1.00)$. No patients in the study developed SIRS or were re-admitted to hospital due to sepsis complications, within one month following TURP. 


\section{Discussion}

Life expectancy has markedly changed in Sub-Saharan Africa during the last decades. With an aging population, the pathology is also changing and the number of men with BPH are steadily increasing [15].

The majority of patients undergoing TURP at KCMC are elderly, presenting in a late stage with BOO and indwelling catheter treatment since weeks or months. They often come from far away villages. This group of men and the perioperative antibiotic coverage is the focus of this study.

Most guidelines recommendations on antimicrobial prophylaxis in conjunction with TURP are based on two systematic reviews and one more recent multi-center study $[7,8,10,16]$ including only patients with pre-operative sterile urine. Therefore, the majority of international guidelines give no high level of evidence regarding the optimal peri-operative antimicrobial regimen in patients with $\mathrm{BOO}$ and catheter treatment.

These men will be colonized with a variable bacterial flora most frequently gram negative uro-pathogens but also gram positive contamination [13]. Bacteriuria is a well-established risk factor in conjunction with endo-urological interventions, which is highlighted in international documents and guidelines such as the European Association of urology [17] and the Infectious Diseases Society of America [18]. The level of contamination of the surgical field (i.e. urethra, prostate, and bladder) during TURP for this elderly catheterized group of men is considered as contaminated. This is different from those without pre-operative bacteriuria/catheterization who undergo a clean-contaminated procedure [19].

It is good practice to prevent infectious complications after contaminated endo-urological procedures, as the risk of febrile UTI and sepsis is clearly increased [13, 16-19]. The European Association of Urology (EAU) guidelines on urological infections recommends in this category of men medical control of bacteriuria for 3 to 5 days followed by perioperative antibiotic coverage [17].

Routine practice at our institution has been for many years to give a long antibiotic course (eight days). However, such regimen increase the risk of bacterial resistance and drug side events, is associated with higher costs. To avoid an overuse of antimicrobial agents, we decided to investigate the efficacy of a three day peri-operative course in this contaminated group of men undergoing TURP, with the intention of preventing infectious complications related to the procedure rather than to eradicate all bacterial strains in the surgical field which has shown to be difficult [13].

This study demonstrates that a short-course was not inferior to a long-course in the targeted group of men with Acute Urinary Retention (AUR). This was true for both the recurrence of bacteriuria and the incidence of symptomatic UTI at 9-11 days after TURP. There was no significant difference in postoperative pyrexia between the two groups, no patient with sepsis and no re-admission within 30 days after surgery.

However, bacteriuria recurs after surgery in some $40 \%$ of the patients. The exact reason is not well understood. It can be speculated that the microbes are harbored within the urogenital organs affected by chronic and acute inflammation, and detected in the urine, usually without symptoms $[13,19,20]$.

Antibiotic resistance is a global challenge and a rational use of antimicrobial agents is nowadays highly recommended. Antimicrobial Stewardship programs have been developed to educate and improve the use of antimicrobial agents [19]. This study is in line with the efforts to curb the overuse and misuse of antibiotics without jeopardizing the patients' health and the outcome. The urological experience is limited [21-22]. By showing that these two aims are reached, the institution can challenge historical recommendations and modify the routines and encourage other institutions to work in the same direction. The consequences in terms of reduced antibiotic prescription is obvious and as such contribute to reduce both the risk of antibiotic resistance development and hospital costs. Only one type-procedure as TURP can save in our institution in one year five kilogram of ciprofloxacin that could be saved for more needing patients. Extrapolating to the whole African continent and beyond, the environmental and economic benefits is enormous.

The study has limitations due to sample size principally, caused among others to limited resources. However, the size was large enough to demonstrate the non-inferiority of a short-term antibiotic course as compared with the established long-term regimen in protecting this defined patient group from infectious complications in conjunction with TURP. The next step would be to further reduce the length of the course to 24 hours even in this contaminated group of men. A large multi-center study within the East, Central and Southern Africa region, supported by international urological and infectious diseases associations, would help deliver evidence-based recommendations for the sub-Saharan region and for a global audience. 


\section{Conclusion}

A short course antibiotic regime is as effective as a long course in preventing infectious complications in catheterized patients undergoing TURP. We recommend the introduction of the short course regime as routine practice in these patients, which would significantly reduce the perioperative misuse of antibiotics and the risk of antibiotic resistance development. Further larger studies are needed to confirm whether even shorter antibiotic courses are efficacious and safe.

\section{Compliance with ethical standards}

\section{Acknowledgments}

I would like to acknowledge Professor Sia Msuya, Dr Nicholous Ngowi, Professor Magnus Grabe, Dr Richard Venn, Dr Suzie Venn and, lastly but not least, Dr Jasper Mbwambo for their support and advices in making this study and report possible. The abstract linked with this work was published as a conference proceeding in https://aasopenresearch.org/documents/2-82.

This study was partly funded by unrestricted grant from Master's THRIVE 2 grant as an award for best proposal among masters' student in 2016 under Institute of Public Health at Kilimanjaro Christian Medical University College.

\section{Disclosure of conflict of interest}

The authors declared that they have no competing interests.

\section{Statement of ethical approval}

Approval for this study was obtained from Kilimanjaro Christian Medical College Research Ethics Committee with reference number 2109. The trial was retrospectively registered Pan Africa Clinical Trial Register with registration number PACTR201808161376054. All patients provided written informed consent before participation of study.

\section{Statement of informed consent}

Written informed consent was obtained from all patients before enrolment in this study.

\section{Authors' contributions}

OJM designed the study; OJM, JSN, PR, FB and AKM, inputs in the study design and conduct; OJM data collection; OJM, EM and AKM input in the analysis; OJM, SJN, EM and AKM read the final manuscript for scientific content of the paper. All authors read and approved the final manuscript. The datasets used and/or analyzed during the current study are available from the corresponding author on reasonable request.

\section{References}

[1] Parsons JK. Benign prostatic hyperplasia and male lower urinary tract symptoms: epidemiology and risk factors'. Current bladder dysfunction reports. 2010.

[2] Mohee AM, Gascoyne-Binzi D, West R, Bhattarai S, Eardley I, Sandoe JAT. Bacteraemia during Transurethral Resection of the Prostate: What Are the Risk Factors and Is It More Common than We Think? Public Library of Science. 2016.

[3] Vivien A, Lazard T, Rauss A, Laisné MJ, Bonnet F. Infection after Transurethral Resection of the Prostate: Variation among Centers and Correlation with a Long-Lasting Surgical Procedure, France. European Urology. 2001; 39: 272-276.

[4] Wilson JR, Puri R, Prescott S, Urwin GH. The catheterized patient undergoing transurethral resection of the prostate: a survey of the current practice of British urologists, BJU International. 2003; 92(6): 589.

[5] Alsaywid BS, Smith GH. Antibiotic prophylaxis for transurethral urological surgeries: Systematic review. Urol Ann. 2013; 5(2): 61-74.

[6] Kiptoon DK, Magoha GA, Owillah FA. Early Postoperative outcomes of Patients undergoing prostatectomy for benign prostatic hyperplasia at Kenyatta National Hospital, Nairobi. East African Medical Journal. 2007; 84(9). 
[7] Berry A, Barratt A. Prophylactic antibiotic use in transurethral prostatic resection: a meta- analysis. J Urol. 2002; 167: 571-7.

[8] Qiang W, Jianchen W, MacDonald R et al. Antibiotic prophylaxis for transurethral prostatic resection in men with preoperative urine containing less than 100,000 bacteria per ml: a systematic review. J Urol 2005; $173: 1175-81$.

[9] Kutlu SS, Aybek Z, Tekin K, Okke D, Akalin et al. Is short course of antimicrobial therapy for asymptomatic bacteriuria before urologic surgical procedures sufficient? J Infect Dev Ctries. 2012; 6(2):143-147.

[10] Wagenlehner F, Stöwer-Hoffmann J, Schneider-Brachert W, Naber KG, Lehn N. Influence of a prophylactic single dose of ciprofloxacin on the level of resistance of Escherichia coli to fluoroquinolones in urology. Int J Antimicrob Agents. 2000; 15(3): 207-211.

[11] Riedel S, Beekman SE, Heilmann KP, Richter SS, Lomas G, Ferech M, et al. Antimicrobial use in Europe and antimicrobial resistance in Streptococcus pneumoniae. European Journal of Clinical Microbiology and Infectious Diseases. 2007; 26(7): 485-490.

[12] Baten E, Van Der F, Orye C, Arijs CI, Renterghem KV. World Journal of Urology. Antibiotic prophylaxis in TURP: a prospective analysis concerning antibiotic stewardship and a potential reduction of antibiotic use in TURP. 2019.

[13] Grabe M, Forsgren A, Bjork T, Hellsten S. Controlled trial of a short and a prolonged course of ciprofloxacin in patients undergoing transurethral resection of the prostate. Eur J Clin Microbiol. 1987; 6: 11- 17.

[14] Zhong B. How to Calculate Sample Size in Randomized Controlled Trial? J Thorac Dis. 2009 Dec; 1(1): 51-54.

[15] GBD 2016 DALYs and HALE Collaborators. Global, regional and national disability-adjusted life-years (DALYs) for 333 diseases and injuries and health life expectancy (HALE) for 195 countries and territories, 1990-2016: a systematic analysis for the Global Burden of Disease Study 2016. Lancet 2017; 390: 1260-1344.

[16] Wolf JS, Bennett JC, Dmochowski RR, Hollenbeck BK, Pearle MS, Schaeffer JS .Best Practice Policy Statement on Urologic Surgery Antimicrobials Prophylaxis,In:Hubbard H, Colau A, Lucet JC, Rufat P, Botto H, Benoit G, Jardin A. Incidence and risk factors of bacteriuria after transurethral resection of the prostate.France. Eur Urol.2001; 39(3): 272-6.

[17] European Association of Urology. Guideline on Urological Infections version 2015; 56-57.

[18] Nicole LE, Gupta K, Bradley SF, et al. Clinical Practice Guidelines for management of Asymptomatic Bacteriuria: 2019 Update by the Infectious Diseases Society of America.

[19] Grabe MJ, Lundstroem K-E. Tailored perioperative antimicrobial prophylaxis in urological surgery: myth or reality? Current Opinion in Urology. 2017; 27(2): 112-9.

[20] Colau A, Lucet JC, Rufat P, Botto H, Benoit G, Jardin A. Incidence and risk factors of bacteriuria after transurethral resection of the prostate.France. Eur Urol. 2001; 39(3): 272-6.

[21] Schutz EC, Hulscher ME, Mouton JW, et al. Current evidence on hospital antimicrobial stewardship objectives: a systematic review and meta-analysis. Lancet Infect Dis. 2016; 16: 847-56.

[22] Grabe M, Resman F. Antimicrobial Stewardship: what we all just need to know. Eur Urol 2018.

\section{Authors short Biography}

Dr Orgeness Jasper Mbwambo is a junior member of faculty of medicine at Kilimanjaro
Christian Medical University College with interest in Research in Uro-ocology, andrology and
antibiotic stewardship in urology. He graduated doctor of Medicine at MUhimbili University
of Health and Allied Science in 20212. From there, he worked at a district hospital in Arusha
Distric coumcil (Oltrumet Hospital) after doing his internship at Amana Referral Hospital.
He also worked at University of Dodoma for 1 year 2014-2015 before persuing master of
medicine in Urology at Kilimanjaro Christian Medical University College. He also became a
fellow by examination of the College of Surgeons of Southern, Central and East Africa (FCS-
ECSA. Urology) in 2019. He is currently working as a lecturer and urologist in the
department of Urology, Faculty of Medicine at Kilimanjaro Christian Medical University
College and Kilimanjaro Christian Medical Centre respectively.

